\title{
Advances in the continuous culture of planktonic copepods*
}

\author{
E. J. Zillioux ${ }^{1}$ and N. F. LACKIE ${ }^{2}$ \\ ${ }_{1}^{1}$ University of Miami, Rosenstiel School of Marine and Atmospheric Sciences; \\ Miami, Florida, USA, \\ and \\ 2 U.S. Department of the Interior, Federal Water Pollution Control Administration, \\ National Marine Water Quality Laboratory; West Kingston, Rhode Island, USA
}

KURZFASSUNG: Fortschritte bei der kontinuierlichen Kultur planktonischer Copepoden. Einige Verbesserungen für die Konstruktion eines rezirkulierenden Seewassersystems (vgl. ZilLIOUx 1969), das sich für die Aufzucht planktonischer Copepoden eignet, werden beschrieben. Mehrere Kulturen können in einem einzigen rezirkulierendem System getrennt voneinander gehalten werden. Als methodische Neuerungen wurden ein dreistufiger Sedimentierbehälter sowie ein besonderes Absaugverfahren beim Durchschäumen des Seewassers (wodurch eine zu starke Anreicherung an gelösten organischen Substanzen verhindert wird) eingeführt. Acartia clausi und $A$. tonsa konnten über $11 / 2$ Jahre mit Hilfe dieses Systems in großer Individuenzahl gezüchtet werden.

\section{INTRODUCTION}

The development of a system for the continuous culture of planktonic copepods was described by ZnLloux (1969). In this system, which utilizes ciliate control of bacterial population and algal debris, and foam separation as a means to limit accumulation of dissolved organics, the copepods Acartia clausi and A. tonsa have been cultured for over a year with frequent harvesting. It was realized, however, that while successful continuous culture had been obtained, certain improvements would increase the value of this system. First, it was pointed out by Znunoux (1969) that while total dissolved organic carbon (DOC) was reduced by $27 \%$ through the action of the foam tower, this efficiency would probably increase by removing cellular particulates prior to foaming. Secondly, DOC removal should be further improved by modifying the foam tower design to facilitate rapid removal of foam. Thirdly, the

* Scientific Contribution No. 1169 from the University of Miami, Rosenstiel School of Marine and Atmospheric Sciences. Research was done at the National Marine Water Quality Laboratory, West Kingston, R. I. 
system would be applicable to a wider range of requirements if it could be easily modified from a recirculating to a flow-through system.

These modifications, in addition to other minor improvements in the overall design, are reported in this paper.

\section{RESULTS}

Figure 1 is a photograph of the original culture system as described in detail by ZiLlioux (1969), however, it has the glass-wool filter placed before and not after the foam tower.

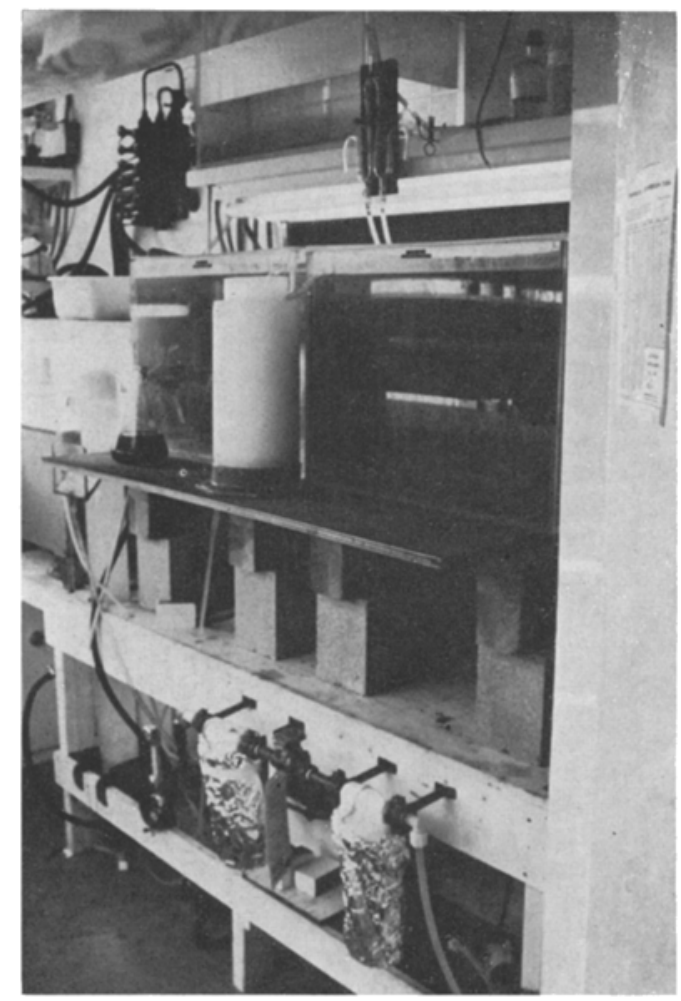

Fig. 1: The original recirculating culture system

Figure 2 is a photograph of one of the newly designed recirculating systems. The two 1001 culture units of the original system have been subdivided into eight 251 units. Each unit is isolated from the others by non-continuous inlet and outlet lines which prevent the possibility of accidental siphoning between units. The multiple-unit construction facilitates experimental design by providing replicate experimental and control tanks. When assessing the effect of an additive, the experimental effluents 
could be routed around the collecting tube to waste. Effluents from the control tanks, with the addition of fresh medium to replace the amount lost, would then be recirculated to all units. This type of control eliminates differences in basic medium through possible variations in metabolic products which sometime complicate interpretation of results from static dish experiments.

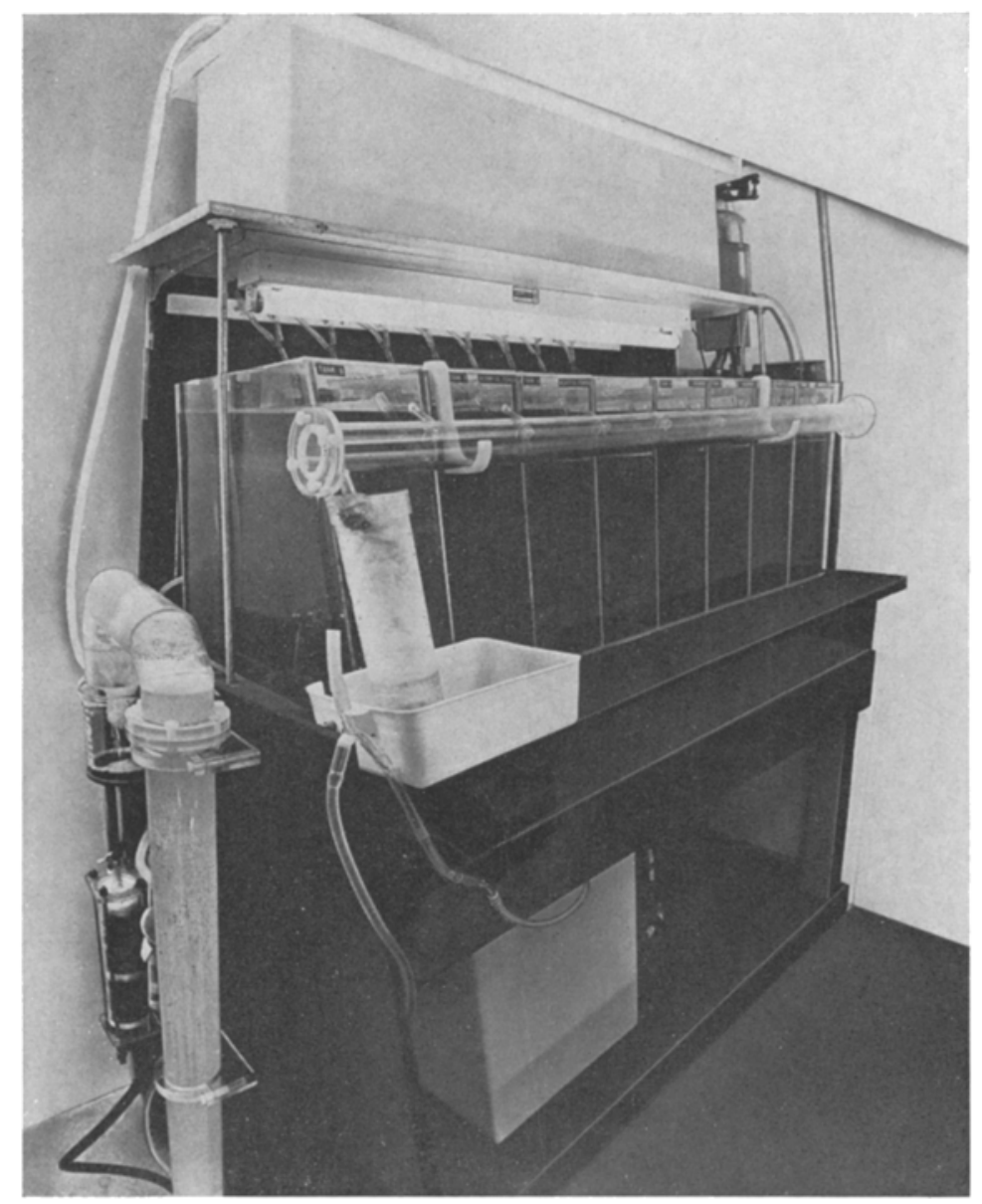

Fig. 2: The new recirculating culture system. Pump and final filters are under bench. Tank distortion was an unavoidable effect from the use of a wide angle lens

The foam tower is modified from a design described by Wallace \& Wilson (1969). The $1.2 \mathrm{~m}$ acrylic tower has an inside diameter of $77 \mathrm{~mm}$ with the air input entering through a $60 \mathrm{~mm}$ diameter fritted glass disc at the base. The top of the tower terminates in a side arm which is inclined at an angle of $95^{\circ}$ from the vertical. Foam produced by bubbling collects in the side arm until a plug is formed and is then forced out by the rising air. The most efficient rate of air flow for production of foam in this 
E. J. ZrLlioux and N. F. LACKIE

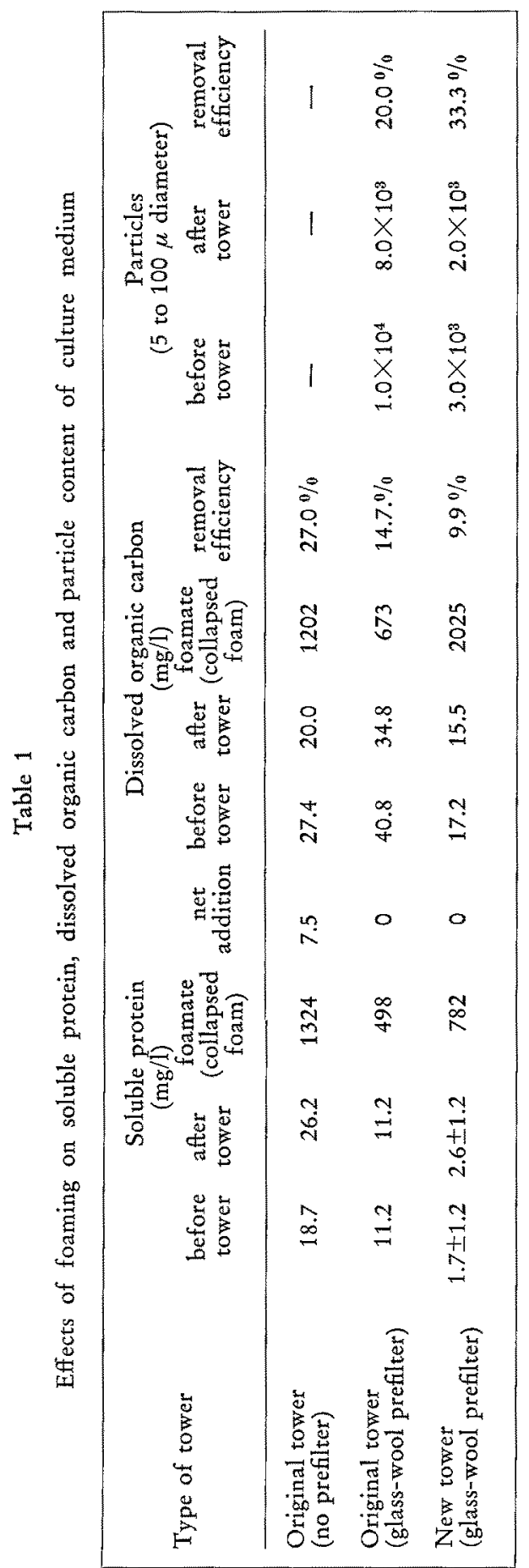


tower is about $400 \mathrm{l} / \mathrm{h}$. During the trial period, flow rate of culture medium has been adjusted to an average of $300 \mathrm{ml} / \mathrm{min}$. Flow rate of the original system has been maintained consistently at $250 \mathrm{ml} / \mathrm{min}$. The new tower is constructed in two sections for easy cleaning and is joined by a bolted flange with a Teflon gasket. The medium inlet is located on the side about $20 \mathrm{~cm}$ below the connecting flange. The outlet is located at the bottom just below the level of air input. This tower replaces a straight glass tube used in earlier work (Fig. 1), which was inherently inefficient in removal of the foam product. All other aspects of the system are described by Zillioux (1969).

A comparison of soluble protein and DOC was made between the original system (data published by Ziluroux 1969), the original system with the glass-wool filter placed before the tower instead of after it, and the new system with glass-wool prefilter and improved foam harvesting. Soluble protein was determined throughout by the Folin procedure (LowRY et al. 1951). DOC was determined in the original system by use of an infra-red carbon analyzer while DOC of samples from the modified systems was determined by wet combustion after the method of Oppentermer et al. (1963). Particle reduction by both foam towers was determined with the use of a Coulter Counter. Results are given in Table 1.

Although protein is no longer added measurably to the recirculating medium, it is apparent from foamate values that considerable addition of soluble protein still occurs within the tower. Comparison of results shows, however, that less protein is released within the tower when a glass-wool prefilter is used to limit the amount of cellular particulates entering the tower. This supports an earlier conclusion that cell lysing within the tower is probably the source of additional protein detected in the foamate. Effect of the new tower design upon froth flotation (the removal of suspended particles by aggregation on bubble surfaces) caused an increase in particle removal efficiency by $13.3 \%$.

DOC values of the original system were all taken under identical conditions except for placement of the glass-wool filter. Values from the new tower, which show considerably less DOC removal efficiency, are not directly comparable with the original system because it was functioning at a lower temperature with different organisms under culture and at a faster flow rate. Although in all cases there is a net decrease in total DOC, the removal efficiency in the original tower was found to be less when the medium was filtered before foaming.

Batoosingh et al. (in press) have found that small particles are important in the aggregation of organic molecules and that better yields of particulate organic matter are obtained when particles are present in the seawater prior to bubbling. It is possible, therefore, that while the reduction of cellular particulates by the prefilter limits the release of dissolved protein within the tower, it is also responsible for limiting aggregation of dissolved organics.

A flow-through modification for the continuous culture system was attempted in order to provide natural conditions of temperature and food, yet assuring retention of the smallest copepod forms. The first attempt featured a column in which two nylon screens were inserted providing final filtration with a $74, \mu$-porosity screen. The system was installed on a barge and the water pumped directly from an intake located about $35 \mathrm{~m}$ distant near the mouth of an estuary. Seawater passed through a coarse 
nylon screen at the intake and was delivered directly to the filtering column. After passing through the column the seawater entered the upper reservoir for distribution to the culture tanks. Effluent from the tank was delivered to waste thus eliminating the use of a glass-wool filter, lower reservoir, level switch, recirculating pump, and final $15 \mu$ and $0.45 \mu$ filters. The filtering column was backflushed once each day. Acartia spp., Penilia sp. (Cladocera) and Artemia salina were maintained in separate culture tanks during the trial period of $2^{1 / 2}$ months. During that time, survival and reproduction were normal and the natural microalgae which passed the filtering column were, apparently, adequate for nutrition of the species selected.

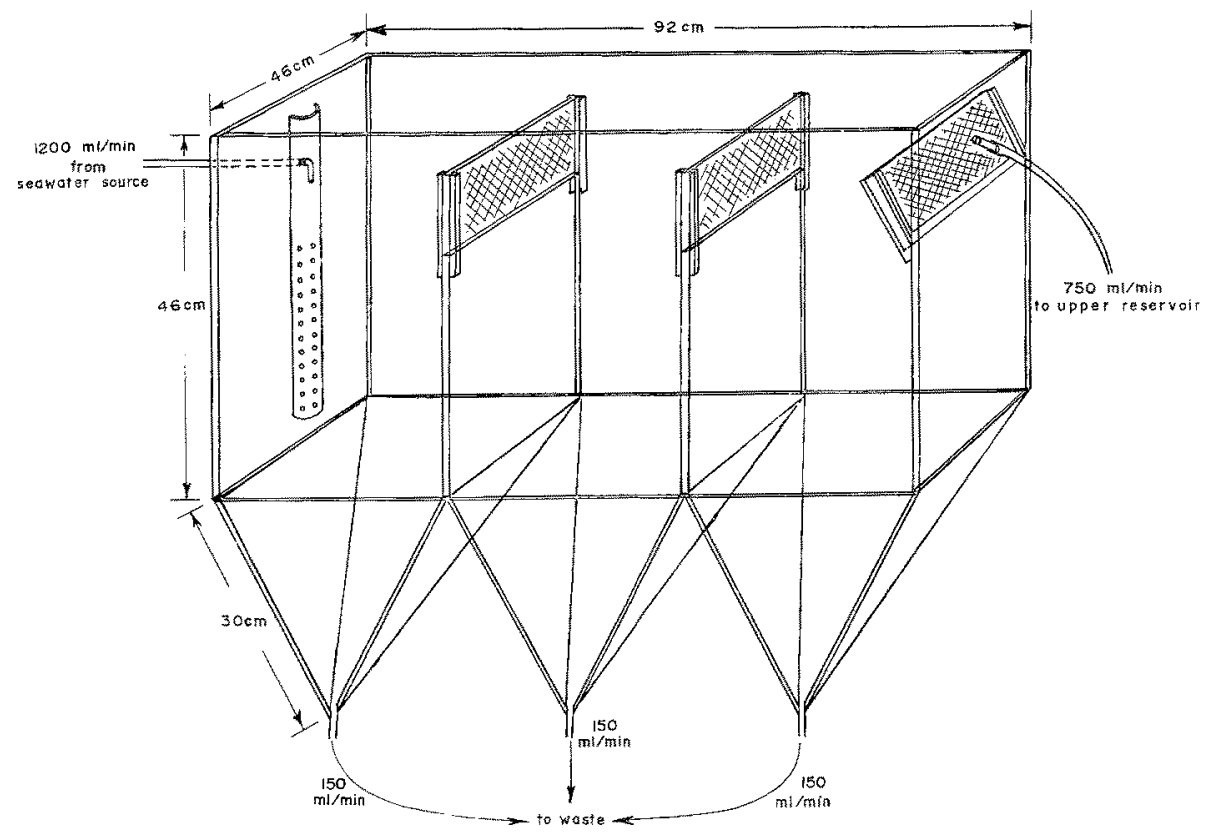

Fig. 3: Drawing of the new filtering and settling tank designed for use in flow-through applications. Cover and supporting frame are omitted for clarity

This flow-through arrangement, however, allowed "contaminating species" such as hydroids, tunicates, small harpacticoid copepods, and mulluscs to enter the culture tanks. Small eggs, trochophore and veliger larvae readily passed the $74 \mu$ mesh of the filtering column. It has been shown, however, that relatively large populations of copepods can be maintained for use in experiments which do not require pure cultures. Where the need for specific organisms with known genetic and nutritional backgrounds is not essential, the flow-through technique simplifies zooplankton culture and more nearly approaches natural conditions.

Information gained from this system was applied to the design of a settling tank (Fig. 3) to replace the filtering column. Avoidance of turbulence for effective settling, and finer filtration should completely eliminate crustacean contaminants. The flow 
rates given in Figure 3 are essential for proper operation of the settling tank and are adjusted by hosecock clamps on tubing connections. Slow continuous flow through the base of each settling compartment avoids rapid $\mathrm{O}_{2}$ depletion in static sediments. Mesh openings of the three removable nylon screens are $250 \mu, 74 \mu$ and $37 \mu$ respectively. The $37 \mu$ mesh has $31 \%$ open area and will readily pass microflagellates found suitable for the support of cultured copepods. Seawater, at a rate of $750 \mathrm{ml} / \mathrm{min}$, is delivered to the upper reservoir. The final delivery rate to the culture tanks is limited to $500 \mathrm{ml} / \mathrm{min}$ and an overflow port added to the reservoir assures maintenance of a constant supply level. The application of foam neoprene rubber, or some similar insulation, to the exterior of the settling tank and upper reservoir will maintain the culture tanks at the natural environmental temperature.

\section{DISCUSSION}

It is still probable that some faunal contaminants will enter the culture tanks in the flow-through system making periodic cleaning of the tank walls necessary. A photographer's squeegee attached to a wooden rod with silicone cement has been found suitable for this purpose. After settling, the resulting debris is removed by siphon. Copepod eggs are also removed, but can be returned by careful siphoning after allowing them to hatch in an appropriate dish. Copepod concentration in the culture tanks is usually high enough, however, so that such conservation is not necessary.

The basic recirculating system has now been in use successfully through 17 months. Physiological and bioassay experiments are planned routinely without seasonal limitations. It is hoped that the new flow-through modification will add new dimension to ecological studies by combining natural field conditions (i. e. temperature, food quality and quantity) with laboratory convenience.

\section{SUMMARY}

1. Construction modifications which improve the efficiency and broaden the versatility of a recirculating culture system for planktonic copepods are described.

2. Folin protein, dissolved organic carbon and particle content have been measured to determine relative efficiencies of two foam towers under different conditions.

3. A combined settling and filtration tank has been designed to facilitate flow-through adaptation of the culture system.

Acknozoledgements. We are grateful to $\mathrm{H}$. Foulk and J. CARDIN for their valuable assistance during the installation and trial of the culture systems, and to Dr. E. Corcoran for making available his wet combustion apparatus for the determination of dissolved organic carbon. 


\section{LITERATURE CITED}

Batoosingh, E., KeSHWAR, B. \& Rilex, G. A., 1969. An analysis of experimental methods for producing particulate organic matter in seawater by bubbling. Deep Sea Res. 16, 213-220.

Lowry, O. H., Rosebrough, N. J., Farr, A. L. \& Randalx, R. J., 1951. Protein measurement with the Folin phenol reagent. J. biol. Chem. 193, 265-275.

Oppenheimer, C. H., Corcoran, E. F. \& Arman, J. van, 1963. Method for determination of organic carbon in seawater. Limnol. Oceanogr. 8, 487-488.

WaLlaCe, G. T. \& Wilson, D. F, 1969. Foam separation as a tool in chemical oceanography. N. R. L. Rep, 6958.

ZILLIOUX, E. J., 1969. A continuous recirculating culture system for planktonic copepods. Mar. Biol. 4, 215-218.

First author's address: E. J. ZnLLioux

University of Miami

Rosenstiel School of Marine Atmospheric Sciences

Miami, Florida 33149, USA 